FRAIUE

\title{
Technique simplifiée et non stérile pour la culture d'embryons immatures de tournesol (Helianthus annuus)
}

\author{
MH Paul, H Barthou * \\ INP-ENSAT, CNRS, laboratoire de biotechnologie et amélioration des plantes, \\ 145, avenue de Muret, F-31076 Toulouse cedex, France
}

(Reçu le 8 juillet 1993; accepté le 24 mai 1994)

\begin{abstract}
Résumé - On décrit une méthode simple ne faisant pas appel à la technique in vitro stérile pour la culture d'embryons immatures de tournesol. Ceux-ci sont directement placés sur papier filtre imbibé d'une solution nutritive commerciale puis, lorsque leurs cotylédons se sont écartés et sont devenus chlorophylliens, les embryons sont repiqués sur terreau. Toutes ces opérations sont réalisées en conditions non stériles. Les plantes obtenues sont plus vigoureuses, elles ont une production de graines accrue et un cycle complet de végétation plus court que celles issues de culture in vitro classique.
\end{abstract}

culture d'embryon / culture non stérile / Helianthus annuus = tournesol

Summary - Simplified and non-sterile technique for the cultivation of immature embryos of sunflower (Helianthus annuus). A simplified technique for the culture of immature embryos of sunflower (Helianthus annuus) is presented. This technique does not use the sterile in vitro method usually applied to the culture of immature sunflower embryos. Immature embryos are first placed on a filter paper imbibed with a commercial nutritive solution and then directly transferred to compost at the chlorophyllian stage of cotyledons. All these operations are achieved under nonsterile conditions. This quite simple process provides more vigorous plants, with increased seed production and a complete vegetation cycle which is shorter than that observed with the classical in vitro method.

embryo culture / non-sterile culture / Helianthus annuus = sunflower

\section{INTRODUCTION}

En amélioration des plantes, on recherche souvent des techniques permettant de raccourcir les temps de sélection et de fixation des caractères en réduisant la durée entre 2 générations successives.

Dans cette optique la culture d'embryons immatures est largement utilisée car elle suppri- me le temps nécessaire à la maturation et à la levée de dormance des graines (Alissa et al, 1986 ; Azpiroz et al, 1987). Dans le cas du tournesol, le cycle végétatif est ainsi ramené à environ $80 \mathrm{j}$, c'est-à-dire que la méthode permet de réaliser de 4 à 5 générations par an au lieu d'une seule en culture normale.

La culture classique d'embryons fait appel aux techniques de culture in vitro stérile et nécessite donc des équipements spécifiques. Dans cet

\footnotetext{
* Correspondance et tirés à part
} 
article nous proposons une technique simplifiée de culture d'embryons de tournesol en milieu non stérile, plus facile à mettre en œuvre et donnant des résultats identiques sinon meilleurs que la technique classique.

\section{MATÉRIEL ET MÉTHODES}

Le travail décrit ici a été réalisé sur les variétés commerciales de tournesol (Helianthus annuus) Sunstar, Oscar et Denario dont les embryons immatures ont été cultivés selon la technique in vitro classique et la technique simplifiée.

\section{Technique classique in vitro}

Celle-ci a déjà été décrite en détail par exemple par Chandler et Beard (1983), Espinasse et al (1985) et Alissa et al (1986). Rappelons que les embryons sont généralement prélevés, en fonction du génotype, 8 à $10 \mathrm{j}$ après la fécondation. Ils sont désinfectés pendant 10 min dans une solution d'hypochlorite de calcium (5\%) puis rincés au moins 3 fois avec de l'eau distillée stérile et isolés, par simple dissection des téguments avec scalpel et pinces précelles, dans des conditions d'asepsie rigoureuse. Les embryons ainsi isolés sont mis en culture sur un milieu préalablement stérilisé et coulé en boîtes de Pétri. II s'agit d'un milieu dit d'initiation de Murashige et Skoog (1962), dont les concentrations en macroéléments ont été réduites de moitié, additionné de saccherose $(3 \%)$, de gélose $(8 \%)$, d'un complexe de vitamines (glycine, biotine, myo-inositol, acide nicotinique, pyridoxine $\mathrm{HCl}$ et thiamine $\mathrm{HCl}$; Alissa et al, 1986) et de 2 phytohormones $\left(0,01 \mathrm{mg} \mathrm{l}^{-1}\right.$ de benzylaminopurine ou BAP et $011 \mathrm{mg} \mathrm{l}^{-1}$ d'acide naphtalèneacétique ou ANA). Les buîtes de Pétri sont hermétiquement fermées avec du parafilm et mises en chambre de culture dans les conditions suivantes: durée du jour $16 \mathrm{~h}$, de la nuit $8 \mathrm{~h}$ et une température constante de $25^{\circ} \mathrm{C}$.

Au bout de 3 à $5 \mathrm{j}$ lorsque les cotylédons sont devenus chlorophylliens et se sont écartés, touicurs en condition d'asepsie, les embryons sont transférés sur un milieu d'enracinement (identique au milieu d'initiation mais sans les phytohormones) pendant 8 à $10 \mathrm{j}$, c'est-à-dire jusqu'à l'apparition d'un système racinaire assez développé. Les plantules ainsi obtenues sont alors mises en acclimatation puis repiquées sur terreau et placées dans une serre.

\section{Technique simplifiée et non stérile}

Dans cette technique toutes If - opérations effectuées de l'extraction des semences 4 ' , apitule ju , u'au repiquage sur terreau, sont réalisées ans prote ion particulière directement sur une paillasse de lab. atoire ou dans la serre.
Quatre à $6 \mathrm{j}$ après le stade retenu pour la technique classique in vitro, c'est-à-dire 12 à $15 \mathrm{j}$ après la fécondation, mais impérativement avant le début de la maturité physiologique de la graine (avant la coloration des téguments), les semences sont prélevées et mises à tremper 10 à 15 min dans de l'eau courante afin de rendre plus aisée leur dissection. Ce stade de prélèvement facilite la manipulation des embryons et permet une meilleure germination (les prélèvements au même stade que dans la méthode classique sont plus délicats et peuvent entraîner plus de pertes à la dissection et une germination plus lente, d'où des risques d'anomalies). Les embryons sont isolés et placés au fur et à mesure dans une coupelle contenant également de l'eau courante. Nous avons constaté que ce trempage d'approximativement $10 \mathrm{~min}$, outre le fait de faciliter les manipulations tout en empêchant la dessiccation de l'embryon, améliore le taux de réussite. Les embryons sont ensuite transférés sur papier filtre (Whatman $n^{\circ} 3$ ), non stérilisé et imbibé d'une solution nutritive commerciale, dans des boîtes de Pétri (nous avons utilisé indifféremment des boîtes de diamètre 50 ou $90 \mathrm{~mm}$ en verre ou en polystyrène) n'ayant subi aucune stérilisation particulière et scellées ou non avec du parafilm. Nous avons utilisé indifféremment la solution nutritive Substra ${ }^{\circledR}$ ou la solution Plantes vertes de $\mathrm{KB}^{\circledR}$ diluée avec de l'eau courante selon les recommandations du fabricant.

Les boîtes de Pétri sont placées soit en chambre de culture, avec les mêmes conditions de culture que celles de la technique classique, soit en serre sans conditions particulières. Quand les cotylédons sont devenus chlorophylliens et se sont écartés (également au bout de 3 à $5 \mathrm{j}$ ), les plants sont alors repiqués directement sur un mélange de terre et terreau et placés en salle d'acclimatation ou directement en serre. Les premiers jours, les plantules sont abondamment pulvérisées avec de l'eau courante et les pots sont maintenus recouverts d'une gaze plastique fine (type Agronet ${ }^{\circledR}$ $15 \mathrm{~g})$ afin de maintenir un degré d'humidité élevé. Au bout de 5 à $6 \mathrm{j}$ on retire progressivement la gaze plastique et on arrose les plantes avec la même solution nutritive que précédemment et diluée également selon les recommandations du fabricant.

Précisons que l'utilisation d'eau distillée pour les différents trempages et pour la préparation des solutions nutritives donne les mêmes résultats que ceux obtenus avec l'eau courante. Signalons également que l'on n'observe généralement pas de développement de moisissures durant le séjour des embryons dans les boîtes de Pétri .

\section{Mesures}

Pour les données présentées ici nous avons, dans un premier temps, compté le nombre de plantes acclimatées obtenues pour 100 embryons mis en culture, par l'une ou "zutre des méthodes. Ensuite, pour chaque variété et chaque technique, nous avons mené à maturité en serre de 16 à 22 plantes réparties au 
hasard en un seul bloc. Sur ces plantes, nous avons noté le nombre de feuilles opposées et alternes et le nombre de graines et mesuré la longueur et le diamètre de la tige, le diamètre du capitule ainsi que la surface foliaire.

\section{RÉSULTATS ET DISCUSSION}

Dans la méthode classique in vitro le pourcentage de plantes obtenues à partir d'embryons immatures peut varier sensiblement, de 50 à $100 \%$ suivant le génotype mais également les conditions de culture in vitro. Dans le tableau I nous avons porté les valeurs obtenues pour les variétés Oscar et Denario : le pourcentage de plantes obtenues par la méthode simplifiée est sensiblement le même que dans la culture in vitro classique, voire légèrement supérieur (96 et $94 \%$ respectivement).

On observe également, chez les plantes obtenues par la technique simplifiée, un aspect morphovégétatif proche de celui des plantes cultivées au champ, ce qui constitue un fait important du point de vue du développement. En effet de nombreux travaux ont montré que les plantes issues de culture in vitro peuvent présenter des modifications dans leur morphologie, lesquelles seraient induites par les conditions du milieu, physiques et/ou nutritives (Tran Thanh Van, 1981 ; Azpiroz et al, 1987 ; Pugliesi et al, 1991). Ainsi on a mis en évidence une relation entre la durée du séjour in vitro et l'intensité de l'effet nanisant (réduction de taille des feuilles et des capitules) et également une incidence sur la précocité des plantes (Azpiroz et al, 1987).

Une étude comparative du développement des plantules obtenues selon les 2 méthodes (tableau II) fait apparaître des réponses au type de technique utilisé différentes selon la nature du paramètre considéré. Ainsi, au stade floraison, il peut ne pas y avoir de différence significative en ce qui concerne le nombre de feuilles ou la longueur totale de la tige. En revanche, le diamètre de la tige, la surface foliaire, le diamètre du capitule et le nombre de graines présentent des différences significatives entre les 2 techniques en faveur de la méthode simplifiée. On a également noté, bien qu'au stade floraison il y ait des feuilles manquantes uniquement dans la partie basale de la tige (feuilles opposées), que la durée de vie des feuilles est généralement plus longue chez les plantes obtenues par la méthode simplifiée.

En ce qui concerne la durée du cycle végétatif, c'est-à-dire du temps s'écoulant entre la mise en culture des embryons et l'obtention des embryons de la génération suivante, on observe une diminution significative. Dans le cas de la variété Sunstar par exemple, pour la technique classique il s'est écoulé $91 \mathrm{j}$, ce qui correspond au temps moyen observé pour le tournesol par d'autres auteurs (Azpiroz et al, 1987) alors que, pour la technique simplifiée, ce temps est ramené à $81 \mathrm{j}$ (différence significative au seuil de $1 \%$ ).

\section{CONCLUSION}

La culture classique in vitro stérile d'embryons immatures de tournesol est une méthode qui requiert une certaine technicité et impose la contrainte de manipulations en conditions stériles (désinfection des semences, préparation des milieux et repiquages) et donc de disposer du matériel spécifique (hotte à flux laminaire, autoclave...).

À l'opposé, la méthode que nous proposons, qui a été testée par ailleurs sur plusieurs génotypes (lignées mâles, femelles et hybrides), est très facile à réaliser, rapide, ne nécessite pas de conditions stériles et est donc nettement

Tableau I. Comparaison du devenir de 100 embryons des variétés Oscar et Denario mis en culture et cultivés par la technique in vitro stérile et simplifiée non stérile.

\begin{tabular}{|c|c|c|c|c|}
\hline & \multicolumn{2}{|c|}{ Technique in vitro } & \multicolumn{2}{|c|}{ Technique simplifiée } \\
\hline & Oscar & Denario & Oscar & Denario \\
\hline Embryons mis en culture & 100 & 100 & 100 & 100 \\
\hline Embryons développés & 99 & 96 & 96 & 94 \\
\hline Plantules enracinées & 87 & 90 & - & - \\
\hline Plantes acclimatées & 87 & 90 & 96 & 94 \\
\hline
\end{tabular}


Tableau II. Moyennes ( \pm erreur standard de la moyenne) de différents paramètres liés au développement mesurés au stade floraison.

Variable Technique in vitro Technique simplifiée Différence significative

Variété Sunstar

Nombre de feuilles opposées

Nombre de feuilles alternes

Longueur de la tige $(\mathrm{cm})$

Diamètre de la tige $(\mathrm{mm})$

Surface foliaire totale $\left(\mathrm{cm}^{2}\right)$

Diametre du capitule $(\mathrm{cm})$

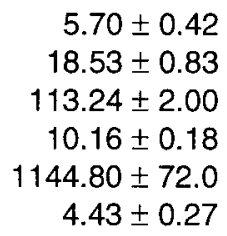

$5.70 \pm 0.42$

$113.24 \pm 2.00$

$4.43 \pm 0.27$

$\begin{aligned} 6.21 & \pm 0.50 \\ 18.31 & \pm 0.63 \\ 112.71 & \pm 2.81 \\ 11.20 & \pm 0.28 \\ 1378.64 & \pm 84.4 \\ 5.86 & \pm 0.31\end{aligned}$

$6.21 \pm 0.50$

$112.71+2.81$

$378.64 \pm 84.4$

$5.86 \pm 0.31$

$$
\begin{aligned}
7.33 & \pm 0.59 \\
9.38 & \pm 0.72 \\
66.43 & \pm 3.85 \\
5.83 & \pm 0.34 \\
361.44 & \pm 43.81 \\
4.42 & \pm 0.23 \\
65.67 & \pm 7.3
\end{aligned}
$$

$\begin{aligned} 7.54 & \pm 0.29 \\ 14.73 & \pm 0.57 \\ 108.02 & \pm 3.47 \\ 7.91 & \pm 0.25 \\ 887.72 & \pm 72.55 \\ 5.89 & \pm 0.25 \\ 123.18 & \pm 10.3\end{aligned}$

-
$\star \star$
$\star \star$
$\star \star$
$\star \star$
$\star \star$
$\star \star$

\section{Variété Denario}

Nombre de feuilles opposées Nombre de feuilles alternes Longueur de la tige $(\mathrm{cm})$ Diamètre de la tige $(\mathrm{mm})$ Surface foliaire totale $\left(\mathrm{cm}^{2}\right)$ Diamètre du capitule $(\mathrm{cm})$ Nombre de graines

$$
\begin{aligned}
5.28 & \pm 0.34 \\
11.00 & \pm 0.77 \\
56.33 & \pm 5.84 \\
5.40 & \pm 0.46 \\
334.04 & \pm 79.6 \\
3.73 & \pm 0.26 \\
59.20 & \pm 6.8
\end{aligned}
$$

$$
\begin{aligned}
5.25 & \pm 0.36 \\
15.06 & \pm 0.79 \\
73.44 & \pm 5.96 \\
6.96 & \pm 0.46 \\
619.19 & \pm 104.0 \\
5.13 & \pm 0.40 \\
111.29 & \pm 18.5
\end{aligned}
$$

Différence significative entre les 2 techniques au seuil de $5 \%\left(^{\star}\right)$ et $1 \%\left(^{\star \star}\right)$ (test de Student).

moins onéreuse à réaliser et moins stressante pour les plantes. II en résulte que les plantes issues de cette technique ont une vigueur accrue et une productivité plus élevée (accroissement du diamètre du capitule). Par ailleurs, le cycle végétatif est sensiblement raccourci (période d'acclimatation moins stressante), ce qui peut permettre de réaliser, par rapport à la technique classique, un cycle supplémentaire dans l'année.

\section{RÉFÉRENCES}

Azpiroz HS, Vincourt P, Serieys H, Gallais A (1987) La culture in vitro des embryons immatures dans l'accélération du cycle de sélection des lignées de tournesol et ses effets morphovégétatifs. Helia 10 , 35-38
Alissa A, Jonard R, Serieys H, Vincourt P (1986) La culture d'embryons isolés in vitro dans un programme d'amélioration du tournesol. C R Acad Sc Paris Série III 302, 161-164

Espinasse A, Lay C, Dybing D (1985) Factors controlling in vitro development of sunflower embryos. agronomie 5, 825-832

Chandler JM, Beard BH (1983) Embryo culture of Helianthus hybrids. Crop Sci 23, 1004-1007

Murashige T, Skoog F (1962) A revised medium for rapid growth and bioassay with tobacco tissue cultures. Physiol Plant 15, 473-497

Pugliesi C, Cecconi F, Mandolfo A, Baroncelli S (1991) Plant regeneration and genetic variability from tissue cultures of sunflower (Helianthus annuus $\mathrm{L}$ ). Plant Breed 106, 114-121

Tran Thanh Van K (1981) Control of morphogenesis in in vitro cultures. Ann Rev Plant Physiol 32, 291311 